\title{
Electrosynthesis of Polyaniline Film on AA 7075 Alloy and Its Corrosion Protection Ability
}

\author{
K. Kamaraj, V Karpakam, S. Sathiyanarayanan, ${ }^{\mathrm{Z}}$ and G. Venkatachari
}

Central Electrochemical Research Institute, Karaikudi 630 006, India

Polyaniline has been electrodeposited on an AA 7075 alloy by a potentiostatic method, and its corrosion protection ability has been studied by Tafel polarization and electrochemical impedance spectroscopic techniques in $1 \% \mathrm{NaCl}$. A pure polyaniline film protects the aluminum alloy up to $70 \%$. However, the corrosion resistance property of the polyaniline film has substantially increased to $90 \%$ by post-treatment in a cerium salt solution. X-ray photoelectron spectra studies have shown that the film formed due to the post-treatment of polyaniline with the AA 7075 alloy in the cerium salt solution is composed of both Ce $\mathrm{C}^{3+}$ and $\mathrm{Ce}^{4+}$ oxides.

(C) 2010 The Electrochemical Society. [DOI: 10.1149/1.3272637] All rights reserved.

Manuscript submitted July 3, 2009; revised manuscript received November 6, 2009. Published January 4, 2010.

The electrodeposition of conducting polymers onto active metals has been a subject of many studies due to their corrosion protection properties of these coatings. A successful electropolymerization requires the formation of a passive layer, which might be able to inhibit the dissolution of the oxidizable metal without blocking the access of the monomer and its further oxidation. Polyaniline (PANI) and its derivatives have been widely studied because of the low potential for polymer formation, easy preparation, and stability of the formed films.

PANI and other conductive polymers have recently been evaluated as corrosion protection coatings for Al alloys. Racicot et al. ${ }^{1,2}$ reported the corrosion inhibition of AA 7075-T6 using a polymer complex comprised of a PANI and a polyelectrolyte, which served as a dopant. They observed a marked reduction in corrosion current for coated samples using Tafel polarization and also found that the electronically conductive form was more protective than the nonconductive form. The corrosion protection performance of PANI and polypyrrole (Ppy) films on AA 2024 and AA 7075 was investigated by Lu et al. ${ }^{3}$ Both polymers, with epoxy overcoats, suppressed pitting corrosion at deliberately formed defects in the coatings on AA 7075. Reduced corrosion currents were also observed on AA 2024, although no marked tendency for the passivation of the alloy was noted by the authors. The use of conductive poly[2,5-bis ( $n$-methyl- $n$-alkylamino) $]$ phenylene vinylenes for the protection of anodized aluminum was described by Zarras et al., ${ }^{4}$ and potentiostatic and galvanostatic measurements of coated and uncoated samples were compared. The polymer-coated samples exhibited a 100-fold decrease in anodic polarization current and reduced pitting.

Besides, studies have been reported for the protection of aluminum by PANI. ${ }^{1,5,6}$ Tallman et al. ${ }^{5}$ presented a review about the use of conducting polymers for corrosion control, paying special attention to the protection given by PANI to aluminum alloys used in aerospace industry such as AA 2024-T3, AA 6061, and AA 7075. Conroy and Breslin ${ }^{6}$ electrodeposited PANI from a tosylic acid solution containing aniline and observed that the electropolymerization was strongly dependent on the applied potential and monomer concentration. Epstein and co-workers ${ }^{7}$ studied the corrosion protection properties of PANI in the emeraldine form and self-doped sulfonated PANI cast-deposited on the AA 3003 and AA 2024-T3 alloys. They found that these coatings were effective in reducing the corrosion rate when the coated electrodes were exposed to chloride environments. They also proposed that the PANI coatings facilitated the extraction of copper from the surface of the AA 2024-T3 alloy and thereby reduced the galvanic coupling between aluminum and copper and reduced the corrosion. Shah et al. ${ }^{8}$ studied the corrosion protection offered by copolymer composites of PANI and Ppy and concluded that it depended on the electrochemical processing vari-

${ }^{\text {z }}$ E-mail: sathya_cecri@yahoo.co.in ables such as applied current density and deposition period. Fujita and Hyland ${ }^{9}$ coated PANI onto an AA 5005 aluminum alloy pretreated in various ways. The authors collected evidence about a chemical interaction between the coating and the metallic surface that varies with the pretreatment of aluminum.

There have been much fewer reports on the direct preparation of PANI at an aluminum electrode. For example, Eftekhari ${ }^{10,11}$ reported the preparation of enzyme-modified PANI coatings at an aluminum electrode from a $0.1 \mathrm{~mol} \mathrm{dm}^{-3}$ solution of aniline in a supporting sulfuric acid solution. However, this appears to be the only report on the direct electrochemical formation of PANI at an aluminum substrate.

Electrodeposition of conducting polymer coatings on aluminum is difficult due to the existence of adherent naturally formed $\mathrm{Al}_{2} \mathrm{O}_{3}$. Husler and Beck ${ }^{12}$ postulated the formation of a porous-type $\mathrm{Al}_{2} \mathrm{O}_{3}$ film parallel to the electropolymerization process. The authors also concluded that both a Ppy film and a porous-type $\mathrm{Al}_{2} \mathrm{O}_{3}$ form on a pretreated aluminum from an aqueous solution containing oxalic acid and pyrrole. It is also reported that the pretreatments are essential for the successful formation of both films (porous $\mathrm{Al}_{2} \mathrm{O}_{3}$ and Ppy film in the pores). Beck and Husler ${ }^{13}$ also reported the formation of a similar type of an $\mathrm{Al}_{2} \mathrm{O}_{3} /$ Ppy composite using some nonaqueous media such as acetonitrile and methanol. Cheung et al. ${ }^{14}$ confirmed the formation of a Ppy film on a thin $\mathrm{Al}_{2} \mathrm{O}_{3}$ film in a propylene carbonate solution. Naoi et al. reported a simultaneous formation of $\mathrm{Al}_{2} \mathrm{O}_{3}$ :Ppy films on an aluminum electrode using sodium $n$-dodecylbenzenesulfonate. ${ }^{15}$ They also suggested that the obtained bilayer film consisted of a "barrier-type" $\mathrm{Al}_{2} \mathrm{O}_{3}$ and an "electronically conducting" Ppy film. Naoi et al. reported about the simultaneous formation of $\mathrm{Al}_{2} \mathrm{O}_{3}$ :Ppy films on an aluminum electrode using some sulfonates. ${ }^{16}$ Martins et al. established that pyrrole electropolymerization on aluminum in an aqueous medium of malic acid consists of a bilayer film composed of a barrier-type $\mathrm{Al}_{2} \mathrm{O}_{3}$ and an electronically conducting Ppy layer. ${ }^{17}$ They also suggested that adherent and homogeneous films can be used as protective coatings against corrosion or as a counter electrode in solid-state capacitors. Earlier studies by Kamaraj et al. ${ }^{18}$ on the galvanostatic electropolymerization of PANI on the AA 7075 alloy have shown that the corrosion protection ability of PANI with the post-treatment of a cerium salt solution is $55-65 \%$. Hence, a study has been made on the corrosion protection behavior of a potentiostatically electrodeposited PANI film on the AA 7075 alloy.

In this paper, the results of the potentiostatic electropolymerization of aniline to produce adherent PANI films on the AA 7075 alloy from an oxalic acid solution are presented.

\section{Experimental}

An aluminum AA 7075 alloy of a 6 in. diameter rod was procured from M/s Virat Aluminum, Mumbai, India. Samples of 1 $\times 10 \mathrm{~cm}$ were cut from the rod after making $1 \mathrm{~cm}$ thick slices. All the chemicals used for electropolymerization and evaluations were 
of analytical reagent grade. Electrochemical measurements were made using a Solartron electrochemical system (model 1280B). A pretreated AA 7075 alloy was used as the working electrode, platinum foil was used as the counter electrode, and a saturated calomel electrode (SCE) was used as the reference electrode.

Pretreatment of $A A$ 7075. - The aluminum alloy was mechanically polished with $1 / 0,2 / 0$, and $3 / 0$ emery papers successively and then dipped in $5 \% \mathrm{NaOH}$ solution for 2 min to activate the surface. After this stage, the samples were cleaned with cleaning powder to remove the black smudge formed over the surface and were washed thoroughly with running water and dipped in a concentrated $\mathrm{HNO}_{3}$ solution for half a minute. The samples were then washed with distilled water and used for electropolymerization.

Electropolymerization of aniline on AA 7075 and its posttreatment.- The pretreated AA 7075 alloy samples were masked with adhesive tape to get an effective working area of $1 \mathrm{~cm}^{2}$ at one of its ends. Electropolymerization was carried out by potentiostatic polarization from the oxalic-acid-based bath with the following composition: $1 \mathrm{M}$ of oxalic acid and $0.5 \mathrm{M}$ of aniline.

The electropolymerization of aniline over the AA 7075 alloy occurred beyond the potential range of $1.7 \mathrm{~V}$ vs SCE. Hence, potentiostatic electropolymerization was carried out at $1.7 \mathrm{~V}$ vs SCE for different durations, and the current transients were recorded. To improve the corrosion protection performance of the electropolymerized PANI layer, a cerium post-treatment was attempted, which involved dipping the electropolymerized coated aluminum alloy samples in a bath containing aqueous cerium chloride (1000 ppm) for half an hour at $60^{\circ} \mathrm{C}$.

Characterization of electropolymerized layers. - FTIR spectroscopy.- The electropolymerized PANI over AA 7075 was scraped, and the IR spectrum of the polymer powder thus obtained was taken using a $\mathrm{KBr}$ pellet in a Nicolet 380 Fourier transform infrared (FTIR) instrument.

Morphology studies. - A scanning electron microscope (SEM, Hitachi, model $\mathrm{S} 3000 \mathrm{H}$, Canada) and an atomic force microscope (AFM, molecular imaging scanning probe microscope, model PICOSPM) were used to characterize the surface morphology of the electropolymerized PANI on an aluminum alloy.

XPS analysis. - The X-ray photoelectron spectra (XPS) of the samples were recorded on a MultiLab 2000 (Thermofisher Scientific, U.K.) fitted with a twin anode X-ray source using $\mathrm{Mg} \mathrm{K} \alpha$ radiation $(1253.6 \mathrm{eV})$. The sample pellets were mounted on the stainless steel sample stubs using conductive silver paint (Agar Scientific Ltd, U.K.). The stub was initially kept in the preparatory chamber overnight to desorb any volatile species at $10^{-9}$ mbar and was then introduced into the analysis chamber having a base pressure of $9.8 \times 10^{-10}$ mbar to record the spectra. High resolution spectra averaged over five scans with a dwell time of $100 \mathrm{~ms}$ in steps of $0.05 \mathrm{eV}$ were obtained at a pass energy of $20 \mathrm{eV}$ in the constant analyzer energy mode. The binding energy was referenced with $\mathrm{C} 1 \mathrm{~s}$ at $284.98 \mathrm{eV}$ within an accuracy of $\pm 0.05 \mathrm{eV}$.

Corrosion resistance property evaluation.- The AA 7075 alloy samples having an electropolymerized PANI coating over it were evaluated for their corrosion resistance property in aerated $1 \% \mathrm{NaCl}$ by Tafel polarization and electrochemical impedance spectroscopy (EIS). Both the Tafel polarization and EIS measurements were carried out after a 30 min immersion in $1 \% \mathrm{NaCl}$ solution.

In the Tafel polarization method, the scanning of potential was done from $-0.2 \mathrm{~V}$ vs the open-circuit potential (OCP) to $+0.2 \mathrm{~V}$ vs the OCP at a scan rate of $1 \mathrm{mV} / \mathrm{s}$. From the anodic and cathodic polarization curves, the Tafel regions were identified and extrapolated to the corrosion potential $\left(E_{\text {corr }}\right)$ to get the corrosion current $\left(i_{\text {corr }}\right)$ using CorrView software. The Tafel regions were mostly 30 $100 \mathrm{mV}$ in the studied systems.

In the EIS method, ac signals of $20 \mathrm{mV}$ amplitude and various frequencies from $10 \mathrm{kHz}$ to $0.1 \mathrm{~Hz}$ at $\mathrm{OCP}$ were impressed to the coated aluminum alloys. The impedance values were reproducible by \pm 2 to $3 \%$. From the impedance plots, the charge-transfer resistance $\left(R_{\mathrm{ct}}\right)$ and the double-layer capacitance $\left(C_{\mathrm{dl}}\right)$ values were calculated using ZSimpWin 3.21 software using an equivalent

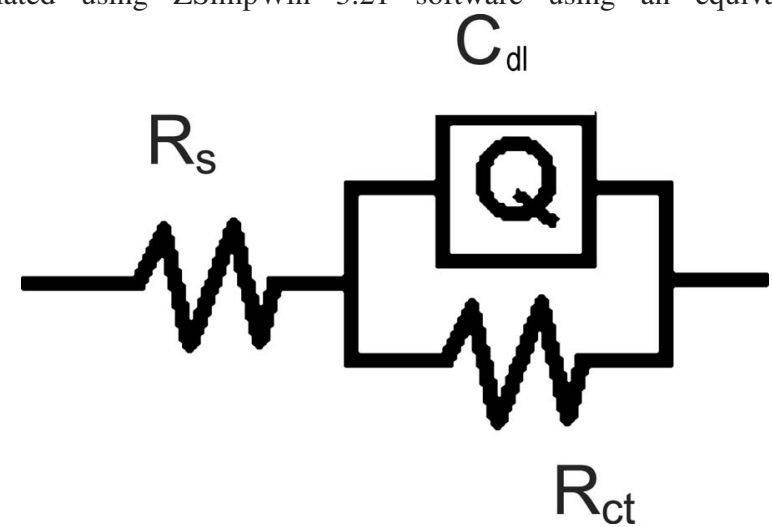

circuit where $R_{\mathrm{S}}$ is the solution resistance, $R_{\mathrm{ct}}$ is the charge-transfer resistance, and $Q$ is the constant phase element (CPE) of the doublelayer capacitance. Because the PANI film on aluminum was in the conducting form, the resistance offered by the polymer film was small and the impedance behavior of the studied frequency region corresponded to the charge-transfer reaction occurring in the aluminum surface. Hence, the equivalent circuit with one time constant was used for the impedance data analysis.

For the description of a frequency-independent phase shift between an applied ac potential and its current response, a CPE was used, which is defined in impedance representation as

$$
Z(Q)=Y_{0}^{-1}(j \omega)^{-n}
$$

where $Y_{0}$ is the CPE constant, $\omega$ is the angular frequency (in $\left.\operatorname{rad} \mathrm{s}^{-1}\right), j^{2}=-1$ is the imaginary number, and $n$ is the CPE exponent $[n>0$, for ideal capacitance $Z(\mathrm{CPE})=C, n=1]$. The following equation was used to convert $Y_{0}$ into $C_{\mathrm{dl}}{ }^{19}$

$$
C_{\mathrm{dl}}=Y_{0}\left(\omega_{\mathrm{m}}^{\prime \prime}\right)^{n-1}
$$

where $C_{\mathrm{dl}}$ is the double-layer capacitance and $\omega_{\mathrm{m}}^{\prime \prime}$ is the angular frequency at which $Z^{\prime \prime}$ is the maximum. Because PANI coating is conductive, the resistance of the coating is negligible and the impedance behavior represents the charge-transfer process of the aluminum alloy dissolution. From the measured charge-transfer resistance values, the protection efficiency of the coating was obtained from the relationship

$$
\text { protection efficiency }(\%)=\frac{R_{\mathrm{ct}(\mathrm{C})}-R_{\mathrm{ct}}}{R_{\mathrm{ct}(\mathrm{C})}} \times 100
$$

where $R_{\mathrm{ct}(\mathrm{C})}$ and $R_{\mathrm{ct}}$ are the charge-transfer resistance values in the presence and in the absence of a PANI coating. From the Tafel polarization studies, the protection efficiencies were obtained from the following equation

$$
\text { protection efficiency }(\%)=\frac{i_{\text {corr }}-i_{\text {corr }(\mathrm{C})}}{i_{\text {corr }}} \times 100
$$

where $i_{\text {corr }}$ and $i_{\text {corr(C) }}$ are the corrosion current values in the absence and in the presence of PANI coatings.

\section{Results and Discussion}

Electropolymerization under potentiostatic condition.- A potentiostatic current density-time $(I-t)$ transient for PANI deposition on the aluminum alloy electrode at an applied potential of $1.7 \mathrm{~V}$ is shown in Fig. 1. It is observed from the figure that the current drops sharply at the beginning due to the electrodeposition of the electrolyte and the monomer. In the second stage, the current increases due to the formation of $\mathrm{Al}_{2}\left(\mathrm{C}_{2} \mathrm{O}_{3}\right)_{3}$. In the final stage, the current starts to decrease, which is due to the formation of polymer on the alumi- 


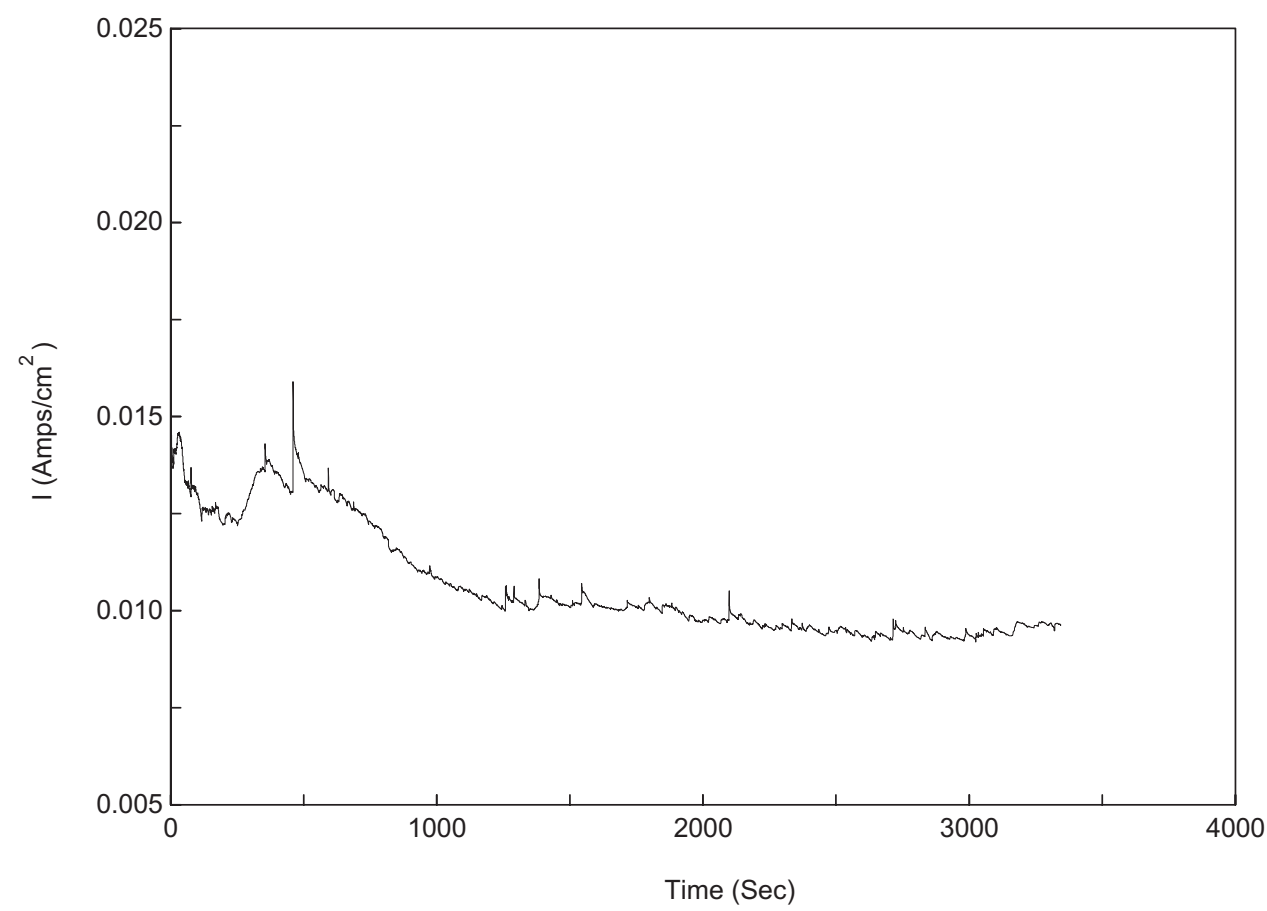

Figure 1. I- $t$ transient of potentiostatic polymerization of aniline on the AA 7075 alloy at $1.7 \mathrm{~V}$.

num substrate. The three distinct stages can be clearly seen for the applied potential, as shown in Fig. 1. A similar mechanism of Ppy formation from an oxalic acid bath was proposed by Akundy and Iroh. $^{20}$

FTIR studies of PANI coating.- Figure 2 shows the FTIR spectra of the electropolymerized layer on the aluminum alloy by a potentiostatic method. The bands around 1670, 1590, and $1490 \mathrm{~cm}^{-1}$ correspond to $\mathrm{C}=\mathrm{O}$ of oxalates and to quinoid and benzenoid rings of PANI, respectively. ${ }^{21,22}$ The band around $1240 \mathrm{~cm}^{-1}$ corresponds to the $\mathrm{C}-\mathrm{N}$ stretching frequency of PANI. The PANI formed under potentiostatic conditions has both quinoid and benzonoid moieties.

Surface morphology studies of PANI coating.- Figure 3 shows the scanning electron micrograph of the electropolymerized PANI coatings over the AA 7075 alloy by a potentiostatic condition. This figure shows the presence of uniform coverage of alloy by the PANI film. This picture also shows the presence of cracks in the coating Tapping mode AFM images yielded information about the surface feature of the polymer film. Figure $4 \mathrm{a}$ and $\mathrm{b}$ shows the surface topography of the electropolymerized PANI aluminum. The threedimensional image of the electropolymerized PANI coating has exhibited a roughness value between 70.4 and $359.4 \mathrm{~nm}$. Both images confirm the presence of cracks in the film.

Corrosion protection evaluation of PANI coating.- Electropolymerized PANI coating on the AA 7075 alloy has been attempted for several durations up to $5 \mathrm{~h}$. The impedance behavior of such coatings in $1 \% \mathrm{NaCl}$ is shown in Fig. 5, and kinetic parameters obtained from EIS are presented in Table I. The charge-transfer resistance $\left(R_{\mathrm{ct}}\right)$ values obtained from the EIS studies correspond to the aluminum oxidation reaction. This has been proved by the studies of Conroy and Breslin, ${ }^{6}$ who have shown from EIS studies that oxida-

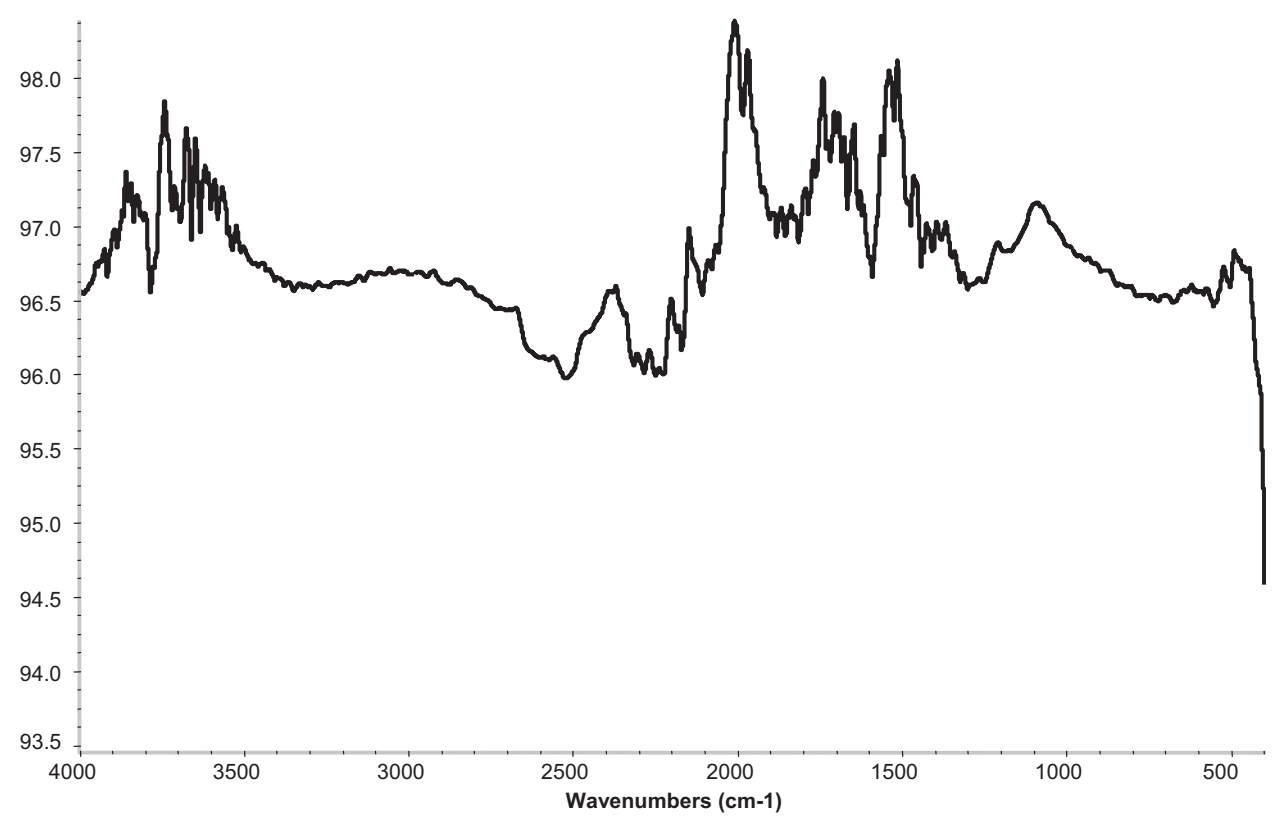

Figure 2. FTIR spectra of electropolymerized PANI on AA 7075 under potentiostatic condition. 


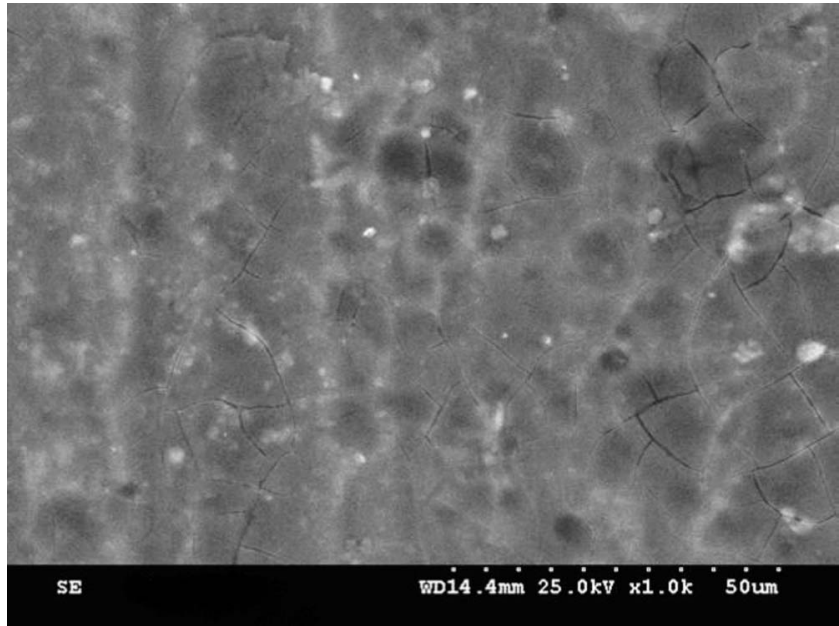

Figure 3. Scanning electron micrograph of potentiostatically formed PANI on AA 7075.

tion of aluminum takes place for PANI-coated aluminum, whereas PANI redox reaction takes place for PANI-coated platinum. It can be seen that the corrosion resistant properties of the coating are not improved with extended electropolymerization times. The $R_{\mathrm{ct}}$ value observed for $3 \mathrm{~h}$ of electropolymerization showed significant protection.

The results of the study with a potentiostatic pulse applied for 3 $\mathrm{h}$ are presented in Table II for various air aging durations of the PANI-coated AA 7075 alloy. The corresponding impedance behavior is shown in Fig. 6. The air aging of the PANI coating has increased the charge-transfer resistance to $10,470 \Omega \mathrm{cm}^{2}$ corresponding to $69 \%$ of protection efficiency for 3 days of aging. The reason for the increased $C_{\mathrm{dl}}$ values with aging is not clear. However, it may be due to the increased permeation of water through the polymer film, which is in a dehydrated state due to aging. Figure 7 shows the polarization behavior of the potentiostatically electropolymerized PANI for $3 \mathrm{~h}$ on the AA 7075 alloy in $1 \% \mathrm{NaCl}$. The corrosion current density derived by extrapolating the anodic and cathodic Tafel lines at $E_{\text {corr }}$ is also given in Table II. With prolonged aging, i.e., after 3 days, the $i_{\text {corr }}$ value is decreased to $9.7 \mu \mathrm{A} / \mathrm{cm}^{2}$ from the blank value of $37 \mu \mathrm{A} / \mathrm{cm}^{2}$. The increase in $i_{\text {corr }}$ values at initial times is due to the galvanic action between the PANI coating and the aluminum surface exposed through the cracks in the coating, which enhanced the localized attack on the aluminum alloy. The Tafel polarization studies give the corrosion current values $\left(i_{\text {corr }}\right)$ of alumi-

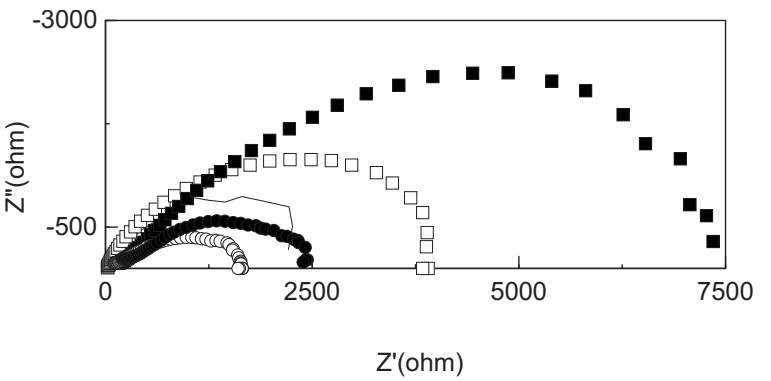

Figure 5. Impedance behavior of electropolymerized PANI on AA 7075 alloy at $1.7 \mathrm{~V}$ (different durations) in $1 \% \mathrm{NaCl}$ - - blank; $\square, 2 \mathrm{~h} ; \mathbf{\square}, 3 \mathrm{~h}$; $\bigcirc$, $4 \mathrm{~h}$; and $0,5 \mathrm{~h}$.

num dissolution in the presence of a polymer coating and not the magnitude of galvanic current flowing between the PANI and the aluminum surface. The electrochemical potential of PANI $(+0.3 \mathrm{~V}$ vs SCE) in the solution is sufficiently anodic to oxidize aluminum ( $E_{\text {corr }}$ of $-0.7 \mathrm{~V}$ vs SCE), and galvanic current flows between the PANI layer and the exposed aluminum surface. ${ }^{2}$ The flow of galvanic current between the PANI coating and the exposed aluminum surface was demonstrated by Wang and $\operatorname{Tan}^{23}$ with the help of a wire beam electrode. Further, they found that a nonuniform PANI coating accelerates the corrosion of aluminum. They also found that the galvanic action between the PANI and aluminum is decreased upon prolonged exposure in the electrolyte. However with air aging of the PANI-coated aluminum alloy, the oxide film on the aluminum surface exposed at the cracked areas may get thickened by the reaction with atmospheric oxygen. ${ }^{24}$ But the emeraldine salt (ES) form of PANI may not change upon exposure to atmospheric oxygen because the electropolymerized PANI is already in the oxidized form. ${ }^{25}$ The mechanism of protection of aluminum alloys by PANI coating has been discussed in detail by Conroy and Breslin. ${ }^{6}$ The ES form of PANI oxidizes the aluminum surface as

$$
2 \mathrm{Al}+3 \mathrm{H}_{2} \mathrm{O} \leftrightarrows \mathrm{Al}_{2} \mathrm{O}_{3}+6 \mathrm{H}^{+}+6 \mathrm{e}
$$

and the reduction of ES of PANI to leucoemeraldine salt as

$$
3 \mathrm{ES}+6 \mathrm{H}^{+}+6 \mathrm{e} \rightarrow 3 \mathrm{LS}
$$

Due to this reaction, the conducting state of PANI is changed to the nonconducting state upon exposure to the $\mathrm{NaCl}$ solution. ${ }^{26}$ However, in the present study, the PANI coating is able to protect nearly $70 \%$ due to the presence of cracks in the film.

These electrochemical test results and also the SEM observation clearly show that the film is porous and cannot provide adequate

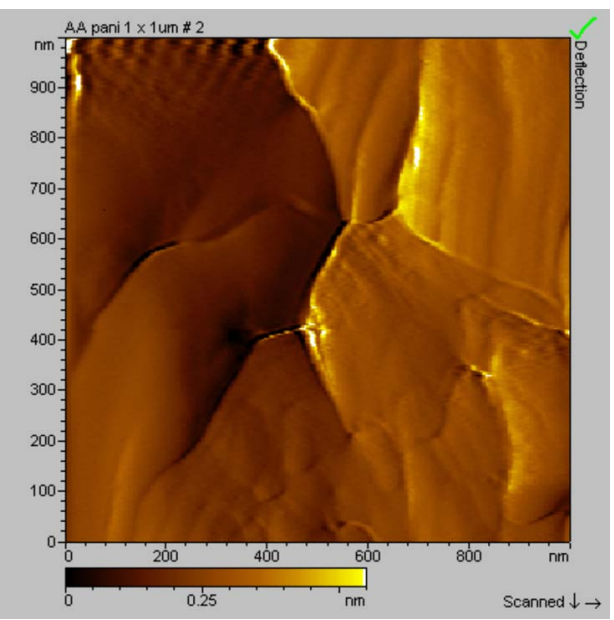

(a)

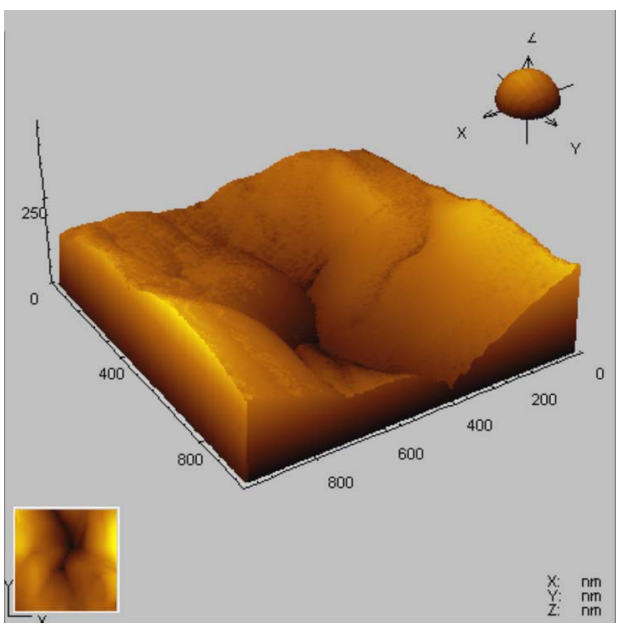

(b)
Figure 4. (Color online) (a) Two- and (b) three-dimensional AFM pictures of electropolymerized PANI on aluminum alloy AA 7075 . 


\begin{tabular}{|c|c|c|c|}
\hline $\begin{array}{l}\text { Duration of electropolymerization } \\
\text { (h) }\end{array}$ & $\begin{array}{c}\text { Charge-transfer resistance } R_{\mathrm{ct}} \\
\left(\Omega \mathrm{cm}^{2}\right)\end{array}$ & $\begin{array}{l}\text { Double-layer capacitance } C_{\mathrm{dl}} \\
\qquad\left(\mu \mathrm{F} / \mathrm{cm}^{2}\right)\end{array}$ & $\begin{array}{l}\text { Protection efficiency } \\
\text { (\%) }\end{array}$ \\
\hline Blank & 3151 & 13.9 & - \\
\hline 2 & 3737 & 13.8 & 15.6 \\
\hline 3 & 8000 & 23.1 & 62.0 \\
\hline 4 & 1873 & 7.3 & - \\
\hline 5 & 3036 & 6.3 & - \\
\hline
\end{tabular}

Table II. Effect of aging on the corrosion protection behavior of electropolymerized PANI on the AA 7075 alloy in $1 \%$ NaCl under potentiostatic conditions at $1.7 \mathrm{~V}$ for $3 \mathrm{~h}$.

\begin{tabular}{|c|c|c|c|c|c|c|}
\hline \multirow[b]{2}{*}{$\begin{array}{l}\text { Air aging } \\
\text { (days) }\end{array}$} & \multicolumn{3}{|c|}{ Impedance method } & \multicolumn{3}{|c|}{ Polarization method } \\
\hline & $\begin{array}{l}\text { Charge-transfer } \\
\text { resistance } R_{\mathrm{ct}} \\
\left(\Omega \mathrm{cm}^{2}\right)\end{array}$ & $\begin{array}{c}\text { Double-layer } \\
\text { capacitance } C_{\mathrm{dl}} \\
\left(\mu \mathrm{F} / \mathrm{cm}^{2}\right)\end{array}$ & $\begin{array}{l}\text { Protection } \\
\text { efficiency } \\
(\%)\end{array}$ & $\begin{array}{l}\text { Corrosion } \\
\text { current } i_{\text {corr }} \\
\left(\mu \mathrm{A} / \mathrm{cm}^{2}\right)\end{array}$ & $\begin{array}{c}\text { Corrosion } \\
\text { potential } E_{\text {corr }} \\
(\mathrm{V} \text { vs SCE) }\end{array}$ & $\begin{array}{l}\text { Protection } \\
\text { efficiency } \\
(\%)\end{array}$ \\
\hline Blank & 3151 & 13.9 & - & 37 & -0.780 & - \\
\hline 1 & 4031 & 15.1 & 6.9 & 107 & -0.720 & - \\
\hline 2 & 5000 & 121.3 & 37 & 60 & -0.579 & - \\
\hline 3 & 10,470 & 193.7 & 69.1 & 9.7 & -0.619 & 74 \\
\hline
\end{tabular}

corrosion protection to the studied aluminum alloy as such. Hence, it is necessary to make a post-treatment that can seal the pinholes and cracked areas of the coating where the bare aluminum is exposed to the aggressive environment. One method is to dip the electropolymerized coated alloy in a bath containing aqueous cerium chloride (1000 ppm) for half an hour at $60^{\circ} \mathrm{C}$.

It has been reported that cerium ions are preferentially deposited over copper-rich regions and reduce the oxygen reduction reaction and hence decrease the corrosion rate of aluminum alloys. ${ }^{27,28}$ The University of Missouri-Rolla has examined the use of cerium-based inhibitors in conversion coatings and primers. ${ }^{29-32}$ In addition, rare earths are generally considered nontoxic. Pioneering researches by Wilson et al. and Hinton et al. found that cerium-based coatings were an environmentally benign alternative to chromate conversion coatings. ${ }^{33-35}$ A recent work by Brack et al. has shown that the coupling of a rare-earth metallic element with a multifunctional organic component produces an inhibitor system that displays synergistic effects between the two components. ${ }^{36}$

Cerium treatment of films that are formed for $3 \mathrm{~h}$ of electropolymerization has shown an increase in $R_{\mathrm{ct}}$ values to $8800 \Omega \mathrm{cm}^{2}$ equivalent to $64 \%$ protection efficiency (Table III), which is higher

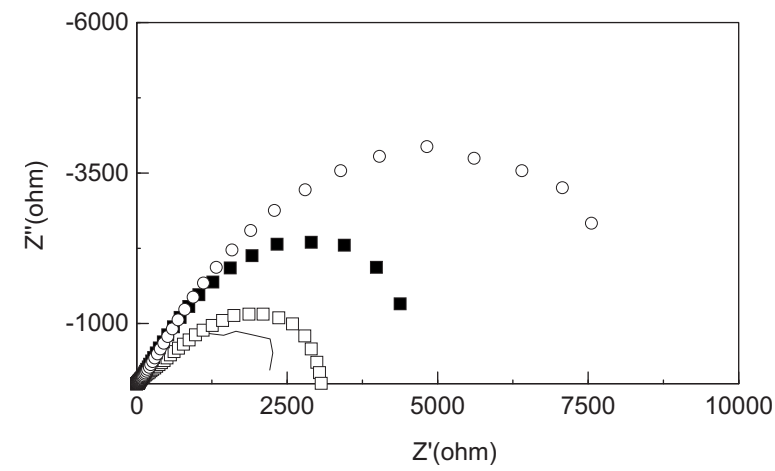

Figure 6. Effect of air aging on impedance behavior of electropolymerized

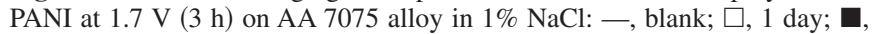
2 days; and $\bigcirc, 3$ days. than that of films without post-treatment. With an extended air aging of 2-3 days, the protection efficiency is increased to more than $90 \%$, as inferred from the impedance behavior (Fig. 8). The Tafel results (Fig. 9) coincide with the impedance results, as shown in Table III. A scanning electron microscopic picture of the cerium-treated PANIcoated aluminum alloy is shown in Fig. 10. Upon comparing with the cerium-free PANI morphology (Fig. 5), it is clearly seen that the cerium treatment resulted in cerium oxide deposition on the cracked areas. It also confirmed that there are no morphological changes due to either air aging or cerium post-treatment. The thickness of the cerium post-treated PANI layers has been measured by an Elcometer thickness meter (model 456), and the thickness is around 12-16 $\mu \mathrm{m}$ and remains unaffected with air aging. However, the observed increase in the charge-transfer resistance values with air aging may be due to the progressive thickening of the $\mathrm{Al}_{2} \mathrm{O}_{3}$ layer, which coexisted with the PANI layer. Braaten et al. reported that the cerium

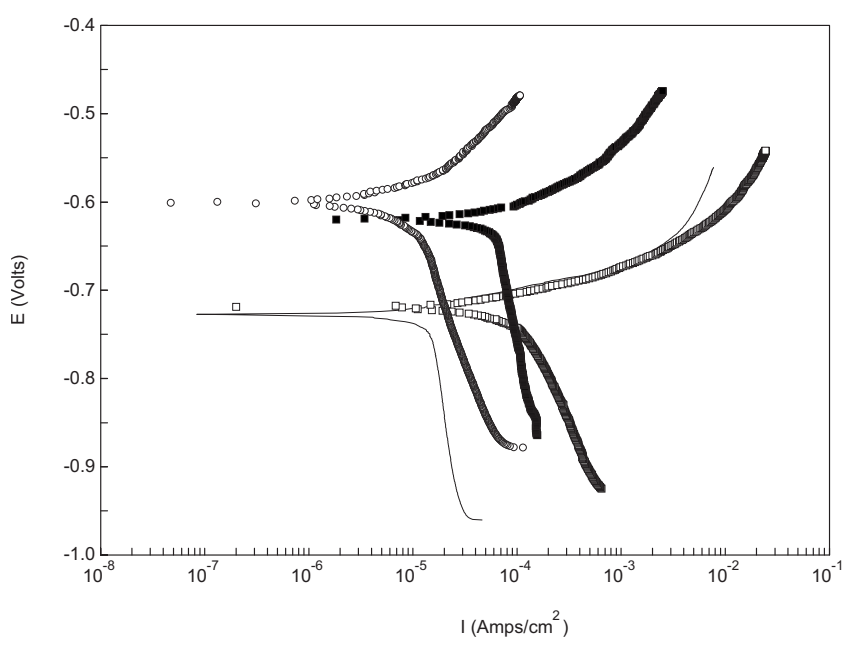

Figure 7. Effect of aging on the polarization behavior of electropolymerized PANI at $1.7 \mathrm{~V}(3 \mathrm{~h})$ coated AA 7075 alloy in $1 \% \mathrm{NaCl}$ - - blank; $\square, 1$ day; -, 2 days; and $O, 3$ days. 


\begin{abstract}
Table III. Effect of cerium salt solution post-treatment on the electropolymerized PANI on the AA 7075 alloy in 1\% NaCl under potentiostatic
\end{abstract} conditions at $1.7 \mathrm{~V}$ for $3 \mathrm{~h}$.

\begin{tabular}{|c|c|c|c|c|c|c|}
\hline \multirow[b]{2}{*}{$\begin{array}{l}\text { Air aging } \\
\text { (days) }\end{array}$} & \multicolumn{3}{|c|}{ Impedance method } & \multicolumn{3}{|c|}{ Polarization method } \\
\hline & $\begin{array}{l}\text { Charge-transfer } \\
\text { resistance } R_{\mathrm{ct}} \\
\left(\Omega \mathrm{cm}^{2}\right)\end{array}$ & $\begin{array}{c}\text { Double-layer } \\
\text { capacitance } C_{\mathrm{dl}} \\
\left(\mu \mathrm{F} / \mathrm{cm}^{2}\right)\end{array}$ & $\begin{array}{l}\text { Protection } \\
\text { efficiency } \\
\quad(\%)\end{array}$ & $\begin{array}{l}\text { Corrosion } \\
\text { current } i_{\text {corr }} \\
\left(\mu \mathrm{A} / \mathrm{cm}^{2}\right)\end{array}$ & $\begin{array}{l}\text { Corrosion } \\
\text { potential } E_{\text {corr }} \\
\text { (V vs SCE) }\end{array}$ & $\begin{array}{l}\text { Protection } \\
\text { efficiency } \\
\quad(\%)\end{array}$ \\
\hline Blank & 3151 & 13.9 & - & 37 & -0.780 & - \\
\hline 1 & 8800 & 6.6 & 65.1 & 12 & -0.562 & 67 \\
\hline 2 & 32,000 & 7.6 & 90.1 & 4.6 & -0.772 & 87 \\
\hline 3 & 68,210 & 8.7 & 95.4 & 7.7 & -0.607 & 80 \\
\hline
\end{tabular}

layer induces a large enhancement in the oxidation of the Ta and $\mathrm{Al}$ substrates at room temperature. ${ }^{37}$ Further, a thin Ce overlayer has a dramatic catalytic effect on the oxidation of polycrystalline $\mathrm{Nb}$ at room temperature. ${ }^{38,39}$ Cerium reacts and forms an interfacial metallic compound or alloy upon evaporation onto an $\mathrm{Al}$ substrate at room temperature. ${ }^{40}$

Figure 11 shows the effect of air aging in the Nyquist representation of the complex impedance of cerium alone treated (without PANI) on the AA 7075 alloy in $1 \% \mathrm{NaCl}$. The charge-transfer resistance $\left(R_{\mathrm{ct}}\right)$ and double-layer capacitance $\left(C_{\mathrm{dl}}\right)$ obtained from these curves are given in Table IV. It shows that the $R_{\mathrm{ct}}$ values increased from 845.1 to $3455 \Omega \mathrm{cm}^{2}$ with prolonged aging due to the oxidized aluminum present in the pores of the cerium coating. However, this value of $R_{\mathrm{ct}}$ is very low compared to that of PANI with cerium treatment (Table II). Hamdy also reported that the direct

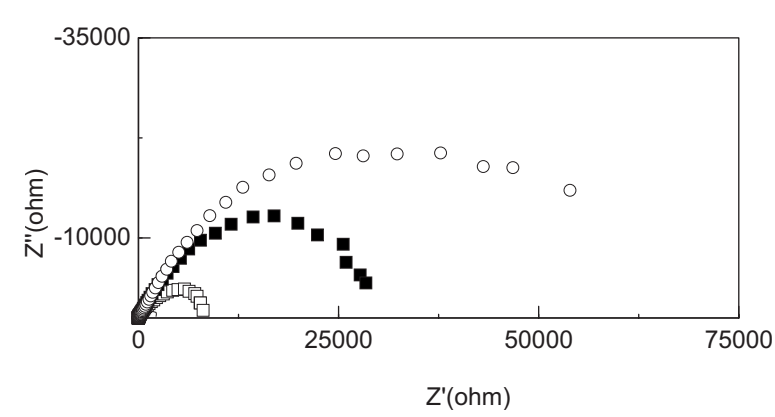

Figure 8. Effect of aging on the impedance behavior of cerium-treated electropolymerized PANI on the AA 7075 alloy in $1 \% \mathrm{NaCl}$ - - , blank; $\square, 1$ day; $\square, 2$ days; and $\bigcirc, 3$ days.

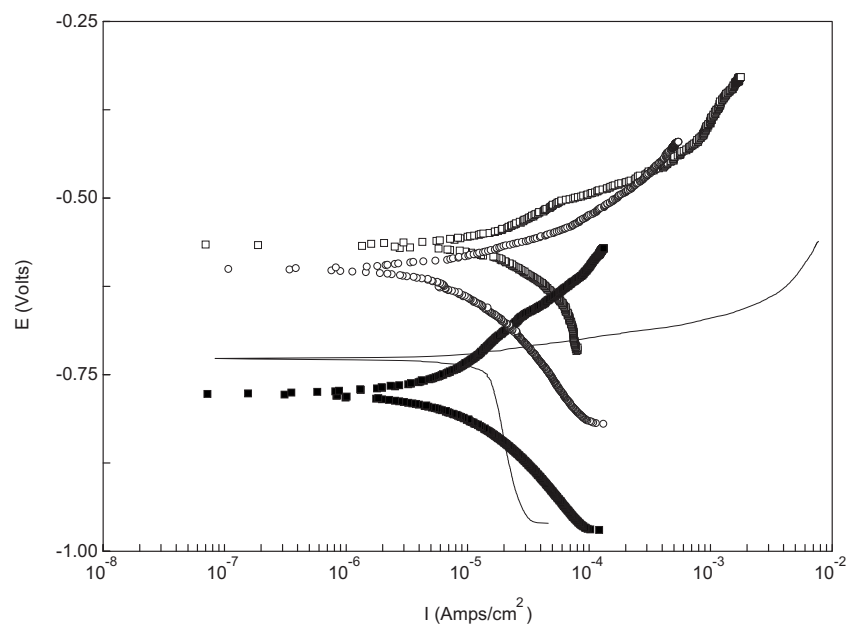

Figure 9. Effect of aging on the polarization behavior of cerium salt solution treated electropolymerized PANI on the AA 7075 alloy in $1 \% \mathrm{NaCl}$ : blank; $\square, 1$ day; $\square, 2$ days; and $\bigcirc, 3$ days. treatment cerium solution does not provide good corrosion protection for aluminum alloys. ${ }^{41}$ They also confirmed the presence of localized corrosion even after a long cerium treatment. The mechanism of corrosion inhibition due to cerium depends on the incorporation of cerium ions through the pores of the $\mathrm{Al}$ oxide layer to block the active surface sites (cathodic inhibitor). ${ }^{41}$ Jakab and Scully established that the corrosion inhibition of AA 2024-T3 is possible with metal ions released from an amorphous $\mathrm{Al}-\mathrm{Co}-\mathrm{Ce}$ alloy located in close proximity to the defect. ${ }^{42}$ They explained that protection of alloys exposed at coating defects is demonstrated by inhibitor ion release in addition to barrier function and sacrificial cathodic protection.

Figure 12 shows the FTIR spectra of the cerium-treated electropolymerized layer on the aluminum alloy by the potentiostatic

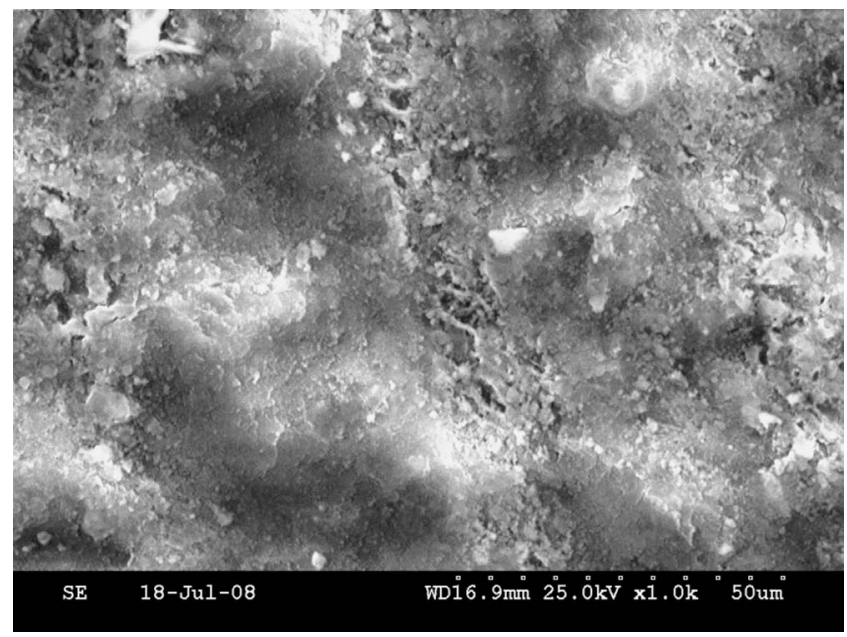

Figure 10. Scanning electron micrograph of cerium salt solution treated PANI on AA 7075 potentiostatically at $1.7 \mathrm{~V}$.

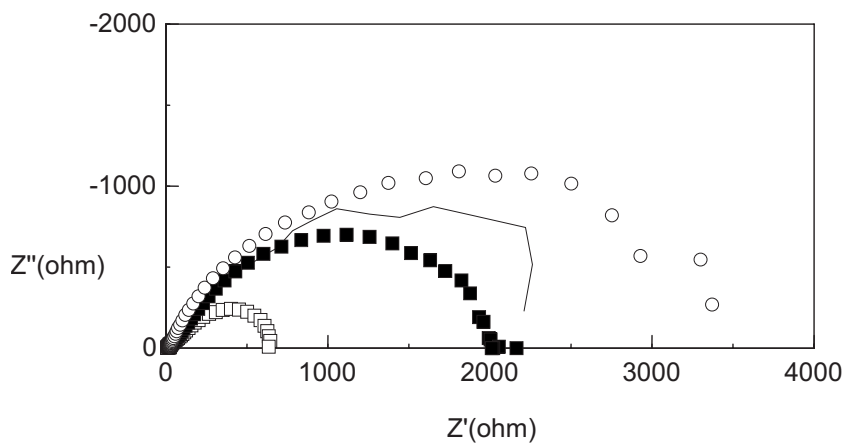

Figure 11. Effect of aging on the impedance behavior of cerium salt solution treated AA 7075 alloy in $1 \% \mathrm{NaCl}$ : —, blank; $\square, 1$ day; $\mathbf{\square}, 2$ days; and $\bigcirc$, 3 days. 


\begin{tabular}{lccc}
\hline \multicolumn{2}{l}{ Table IV. Impedance parameters of cerium salt solution treated AA $\mathbf{7 0 7 5}$ alloy in $\mathbf{1 \%} \mathbf{~ N a C l .}$} \\
$\begin{array}{l}\text { Air aging } \\
(\text { days })\end{array}$ & $\begin{array}{c}\text { Charge-transfer resistance } R_{\mathrm{ct}} \\
\left(\Omega \mathrm{cm}^{2}\right)\end{array}$ & $\begin{array}{c}\text { Double-layer capacitance } C_{\mathrm{dl}} \\
\left(\mu \mathrm{F} / \mathrm{cm}^{2}\right)\end{array}$ & $\begin{array}{c}\text { Protection efficiency } \\
(\%)\end{array}$ \\
\hline Blank & 3151 & 13.9 & - \\
1 & 845.1 & 195 & - \\
2 & 2263 & 67.2 & - \\
3 & 3455 & 16.92 & 8.7
\end{tabular}

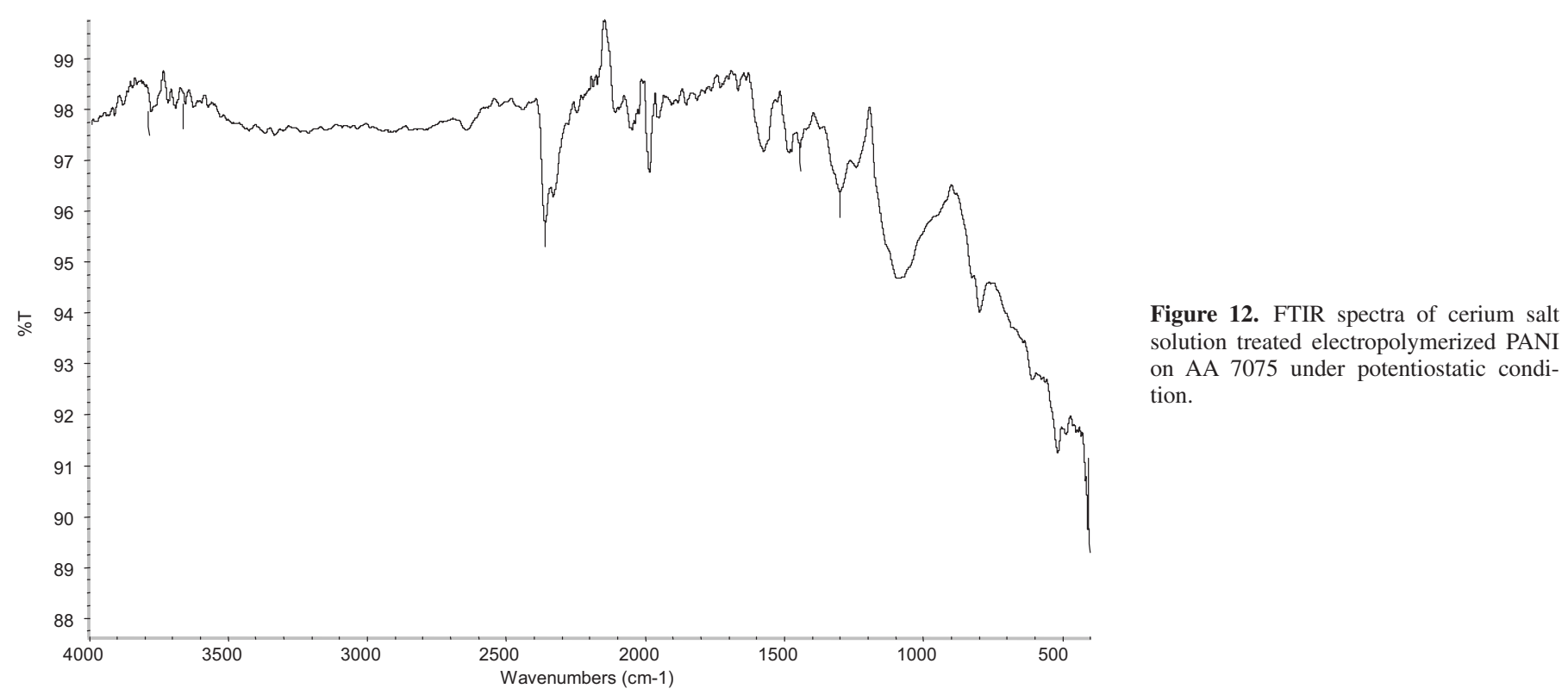

method. The bands around 1670, 1590 and $1490 \mathrm{~cm}^{-1}$ correspond to the $\mathrm{C}=\mathrm{O}$ of oxalates and to quinoid and benzenoid rings of PANI, respectively. The band around $1240 \mathrm{~cm}^{-1}$ corresponds to the C-N stretching frequency, and the spectral peaks at 1574, 1482, 1301 , and $1094 \mathrm{~cm}^{-1}$ are due to PANI; the peak at $510 \mathrm{~cm}^{-1}$ corresponds to the metal oxygen stretching frequency. A similar stretching frequency can also be found in $\mathrm{CeO}_{2}$ and PANI composites. ${ }^{43}$ The metal oxygen stretching frequency of $494 \mathrm{~cm}^{-1}$ in pure $\mathrm{CeO}_{2}$ shifted to $510 \mathrm{~cm}^{-1}$, indicating a weak interaction between cerium oxide and PANI. ${ }^{44}$

The survey XPS acquired from the cerium salt solution treated PANI on the AA 7075 alloy is shown in Fig. 13. It showed the presence of $\mathrm{Ce}, \mathrm{O}, \mathrm{C}$, and $\mathrm{N}$. The $3 \mathrm{~d}$ core level XPS of the cerium salt solution treated PANI on the AA 7075 alloy is also shown in Fig. 14. Pardo et al. ${ }^{45}$ showed several binding energies of $\mathrm{Ce}$, the characteristic satellite of $\mathrm{Ce}^{+4}$ and $\mathrm{Ce}^{+3}$. The $\mathrm{Ce} 3 \mathrm{~d}$ spectra show the components with binding energies of $885.8,903.68,900.8,896.52$, and $881.68 \mathrm{eV}$. The characteristic satellite peaks of $\mathrm{Ce}^{4+}$ are 900.8 and $881.68 \mathrm{eV}$, and others at $885.8,903.68$, and $896.52 \mathrm{eV}$ are characteristic of $\mathrm{Ce}^{3+} .{ }^{46}$ The presence of $\mathrm{Ce}^{3+}$ ions in the solution promotes the formation of a conversion coating of $\mathrm{Ce}(\mathrm{OH})_{3}$ on several metal surfaces, forming a thick film composed of $\mathrm{Ce}(\mathrm{OH})_{3}$, $\mathrm{Ce}_{2} \mathrm{O}_{3}$, and $\mathrm{CeO}_{2}$ as

$$
\begin{gathered}
\mathrm{Ce}^{3+}+3 \mathrm{OH}^{-} \rightarrow \mathrm{Ce}(\mathrm{OH})_{3} \\
2 \mathrm{Ce}(\mathrm{OH})_{3} \rightarrow \mathrm{Ce}_{2} \mathrm{O}_{3}+3 \mathrm{H}_{2} \mathrm{O} \\
2 \mathrm{Ce}(\mathrm{OH})_{3}+2 \mathrm{OH}^{-} \rightarrow 2 \mathrm{CeO}_{2}+4 \mathrm{H}_{2} \mathrm{O}+2 \mathrm{e}^{-}
\end{gathered}
$$

The XPS results show that the cerium salt solution treated electropolymerized PANI on the AA 7075 alloy is composed of $\mathrm{Ce}^{+4}$ and $\mathrm{Ce}^{+3}$ oxides. A similar mechanism was proposed by Wang et al. for a Gr/Al composite surface. ${ }^{47}$

\section{Conclusion}

An electropolymerized PANI coating on an AA 7075 alloy was obtained from an oxalic acid bath by a potentiostatic method. FTIR

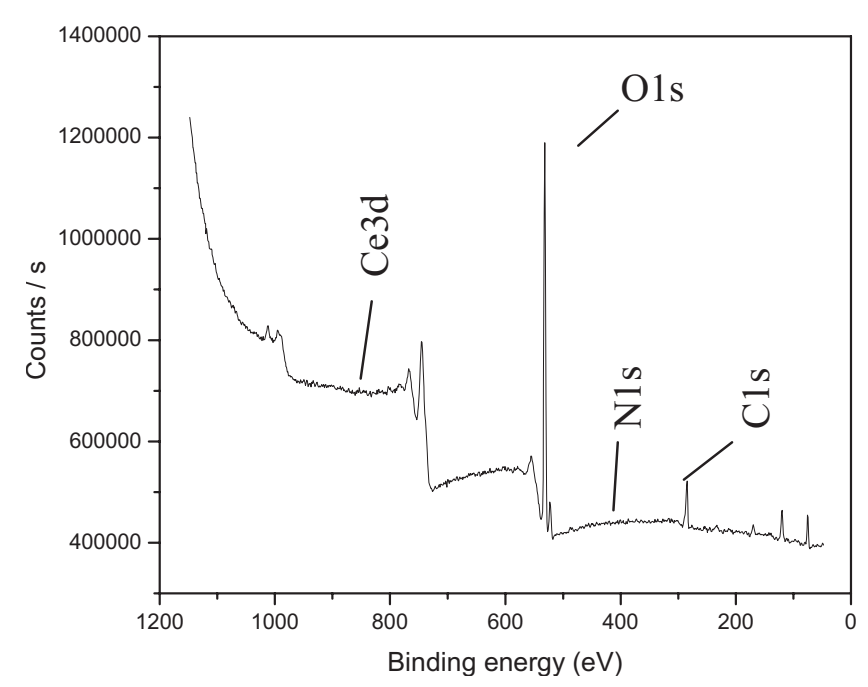

Figure 13. XPS of cerium salt solution treated PANI on AA 7075 alloy. 


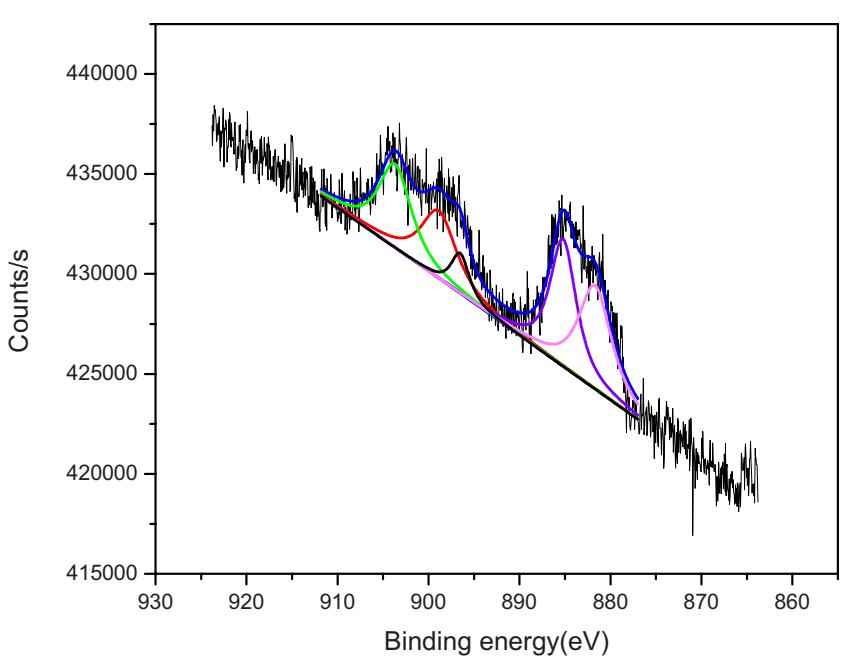

Figure 14. (Color online) Ce $3 \mathrm{~d}$ XPS of cerium-treated PANI on the AA 7075 alloy.

spectroscopy studies have revealed the presence of both benzenoid and quinoid structures, confirming the presence of a partially oxidized PANI (ES), which is known for its conducting nature. Surface morphological studies have shown that the PANI coating on the aluminum alloy has numerous surface cracks. The PANI coating offers a marginal corrosion protection of the AA 7075 alloy in 1\% $\mathrm{NaCl}$ due to the presence of cracks and pinholes in the coating. However, the post-treatment of the PANI-coated Al alloy by immersion in hot cerium salt solution offers a better corrosion protection ability than that of the PANI coating without post-treatment due to the formation of both $\mathrm{Ce}^{3+}$ and $\mathrm{Ce}^{4+}$ oxides on the aluminum surface. The FTIR and XPS studies have confirmed the formation of $\mathrm{Ce}^{3+}$ and $\mathrm{Ce}^{4+}$ oxides on the surface along with PANI on the AA 7075 alloy.

\section{Acknowledgment}

The authors thank the director of CECRI for his kind permission in carrying out this work. The authors also thank DRDO, New Delhi for financial assistance.

\section{References}

1. R. J. Racicot, R. L. Clark, H. B. Liu, S. C. Yang, M. N. Alias, and R. Brown, Mater. Res. Soc. Symp. Proc., 413, 529 (1996).

2. R. J. Racicot, R. Brown, and S. C. Yang, Synth. Met., 85, 1263 (1997)

3. W. K. Lu, S. Basak, and R. L. Elsenbaumer, in Handbook of Conducting Polymers, 2nd ed., T. A. Skotheim, R. L. Elsebaumer, and J. R. Reynolds, Editors, p. 881, Marcel Dekker, New York (2007).

4. P. Zarras, J. D. Strenger-Smith, and M. H. Miles, Polym. Mater. Sci. Eng., 76, 589 (1997).
5. D. E. Tallman, G. Spinks, A. Dominis, and G. G. Wallace, J. Solid State Electrochem., 6, 73 (2002).

6. K. G. Conroy and C. B. Breslin, Electrochim. Acta, 48, 721 (2003).

7. A. J. Epstein, J. A. O. Smallfield, H. Guan, and M. Fahlman, Synth. Met., 102, 1374 (1999).

8. K. Shah, Y. Zhu, G. S. Akundy, J. O. Iroh, and O. Popoola, Key Eng. Mater, 197, 111 (2001).

9. J. Fujita and M. M. Hyland, Int. J. Mod. Phys. B, 17, 1164 (2003).

10. A. Eftekhari, Synth. Met., 125, 295 (2001).

11. A. Eftekhari, Sens. Actuators B, 80, 283 (2001)

12. P. Hüsler and F. Beck, J. Appl. Electrochem., 20, 596 (1990).

13. F. Beck and P. Husler, J. Electroanal. Chem., 280, 159 (1990).

14. K. M. Cheung, D. Bloor, and G. C. Stevens, Polymer, 29, 1709 (1988).

15. K. Naoi, Y. Oura, A. Yoshizawa, M. Takeda, and M. Ue, Electrochem. Solid-State Lett., 1, 34 (1998).

16. K. Naoi, M. Takeda, H. Kanno, M. Sakakura, and A. Shimada, Electrochim. Acta, 45, 3413 (2000).

17. J. I. Martins, S. C. Costa, M. Bazzaoui, G. Gonçalves, E. Fortunato, and R. Martins, J. Power Sources, 160, 1471 (2006).

18. K. Kamaraj, S. Sathiyanarayanan, and G. Venkatachari, Prog. Org. Coat., 64, 67 (2009).

19. C. H. Hsu and F. Mansfeld, Corrosion (Houston), 57, 747 (2001).

20. G. S. Akundy and J. O. Iroh, Polymer, 42, 9665 (2001).

21. K. Shah and J. O. Iroh, Surf. Eng., 20, 53 (2004).

22. K. Shah and J. O. Iroh, Synth. Met., 132, 35 (2002).

23. T. Wang and Y. J. Tan, Corros. Sci., 48, 2274 (2006).

24. H. P. Godand, W. B. Jepson, M. R. Bokwell, and R. L. Kane, The Corrosion of Light Metals, p. 6, John Wiley \& Sons, New York (1967).

25. E. T. Kang, K. G. Neoh, and K. C. Tan, Prog. Polym. Sci., 23, 277 (1998).

26. S. F. Cogan, M. D. Gillbert, G. L. Holleck, J. E. Ehrlich, and M. M. Jillson, J. Electrochem. Soc., 147, 2143 (2000).

27. R. L. Twite and G. P. Bierwagen, Prog. Org. Coat., 33, 91 (1998).

28. A. Yağan, N. O. Pekmez, and A. Yildiz, J. Electroanal. Chem., 578, 231 (2005).

29. E. Morris, J. O. Stoffer, T. J. O'Keefe, P. Yu, and X. Lin, Polym. Mater. Sci. Eng. 81, 167 (1999).

30. J. O. Stoffer, T. J. O'Keefe, M. O'Keefe, E. Morris, S. Hayes, P. Yu, and X. Lin, in Proceedings of the 32nd International SAMPE Technical Conference, SAMPE International (2000)

31. W. G. Fahrenholtz, M. J. O'Keefe, H. Zhou, and J. T. Grant, Surf. Coat. Technol., 155, 208 (2002).

32. J. O. Stoffer, T. J. O'Keefe, X. Lin, E. Morris, P. Yu, and S. P. Sitaram, U.S. Pat. 5,932,083 (1999).

33. L. Wilson and B. R. W. Hinton, International Pat. WO 88y06639.

34. B. R. W. Hinton, D. R. Arnott, and N. E. Ryan, Mater. Forum, 9, 162 (1986).

35. B. R. W. Hinton, N. E. Ryan, and D. R. Arnott, Materials Australasia, 19 (1987) 18.

36. D. Ho, N. Brack, J. C. Scully, T. Markley, M. Forsyth, and B. Hinton, J. Electrochem. Soc., 153, B392 (2006).

37. N. A. Braaten, J. K. Grepstad, and S. Raaen, Surf. Sci., 222, 499 (1989).

38. E. E. Latta and M. Ronay, Phys. Rev. Lett., 53, 948 (1984).

39. M. Ronay and E.-E. Latta, Phys. Rev. B, 32, 5375 (1985).

40. S. Raaen, N. A. Braaten, J. K. Grepstad, and S. L. Qiu, Phys. Scr., 41, 1001 (1990).

41. A. S. Hamdy, A. M. Beccaria, and P. Traverso, Surf. Interface Anal., 34, 171 (2002).

42. M. A. Jakab and J. R. Scully, Nature Mater, 4, 667 (2005).

43. N. Parvatikar S. Jain, S. V. Bhoraskar, and M. V. N. Ambika Prasad, J. Appl. Polym. Sci., 102, 5533 (2006).

44. R. Somani, R. Marimuthu, and A. B. Mandal, Polymer, 42, 2991 (2001).

45. A. Pardo, M. C. Merino, R. Arrabal, F. Viejo, and M. Carboneras, J. Electrochem. Soc., 153, B52 (2006)

46. C. D. Wagner, W. M. Rigge, L. E. Davis, J. F. Moulder, and G. E. Muilenberg, Hand Book of X-Ray Photoelectron Spectroscopy, Perkin-Elmer, Eden Prairie, MN (1979).

47. C. Wang, G. Wu, Q. Zhang, and L. Jiang, J. Mater. Sci., 43, 3327 (2008). 